Saskia van Putten*

\title{
Perception verbs and the conceptualization of the senses: The case of Avatime
}

https://doi.org/10.1515/ling-2020-0039

Abstract: Languages differ in their number of basic verbs that describe perceptual experience. Some languages have only two such verbs: one for visual perception and another for non-visual perception. How do speakers of these languages conceptualize sensory perception? To shed light on this question, this paper investigates the perception verbs $m$ j̀ 'see' and $n u$ 'hear/feel/taste/smell' in Avatime (Kwa, Niger-Congo). These verbs are studied together with the constructions in which they occur, using both translated data and spontaneous discourse. Both perception meanings and meanings outside the domain of perception are taken into account. The detailed picture that emerges shows some previously undocumented patterns of perception encoding and enriches our understanding of the conceptualization of the senses more generally.

Keywords: perception verbs, lexical semantics, polysemy, Niger-Congo languages

\section{Introduction}

\subsection{Background}

Do people around the world think about sensory perception in the same way? On the one hand, we might think they do, given that people everywhere use the same sense organs to perceive the world around them. On the other hand, we may expect differences, given that the role of the different sensory modalities in daily life depends on cultural practices, lifestyle and the environment in which people live. One way of approaching this question is by investigating how people talk about perception in different languages (cf. Majid and Levinson 2011). What are the similarities and differences among the languages of the world in their vocabularies and grammatical constructions for describing perceptual experience?

This paper contributes to answering this question by focusing on a subset of perception vocabulary: the basic verbs that describe perceptual experience,

\footnotetext{
*Corresponding author: Saskia van Putten, Centre for Language Studies, Radboud University, PO Box 9103, Nijmegen 6500 HD, The Netherlands, E-mail: s.vanputten@let.ru.nl 
such as English see and hear. It also zooms in on one language: Avatime, a Ghanaian Kwa (Niger-Congo) language. ${ }^{1}$ Avatime has two verbs to refer to perceptual experience: one for vision ( $m$ ’े 'see') and one for the other senses ( $n u$ 'hear/feel/taste/smell'). ${ }^{2}$ The aim is to investigate what this particular verbal encoding pattern could mean for how sensory perception is conceptualized. More specifically, two aspects of the language of perception are investigated: (i) how are the sensory modalities encoded in verbs and grammatical constructions, and (ii) what other meanings are encoded by the basic perception verbs. I will briefly introduce each of these two aspects in turn.

Typological linguistic work investigating the encoding of the sensory modalities in verbs was pioneered by Viberg (1983). He observes that languages differ in their number of basic perception verbs. Whereas some languages, like English, have a verb for each of the five senses (vision, hearing, touch, taste, smell), other languages combine multiple sensory modalities in a single verb. Viberg assumes that such conflations of multiple sensory modalities come into existence through meaning extensions, where a verb that originally refers to a single sensory modality acquires additional meanings. He observes that these meaning extensions follow a hierarchy with vision at the top, then hearing, then touch, then taste and smell. This hierarchy has also been attested for perception verbs in Australian languages (Evans and Wilkins 2000), but counterexamples have also been found (see e.g., Aikhenvald and Storch 2013).

Viberg (1983) assumes that perception verbs that encode multiple sensory modalities are polysemous and that the traditional five senses are the basic concepts of perception to be lexicalized in the languages of the world. However, anthropologists of the senses have argued that the five-senses model is a Western cultural construction (see e.g., Classen 1993). Other cultures may have different ways of thinking about sensory experience. They could for instance view the mind as a sixth sense (Classen 1993: 2) or conceive of a sense of balance (Geurts 2002). From this point of view, the perception verbs of a language can provide insight into a culture's conceptualization of the senses. For instance, Howes (2006) observes that speakers of several Melanesian as well as African languages talk about 'hearing a smell' and connects this to what he calls audio-olfactory synesthesia, i. e., the cultural conflation of the two sensory modalities. Ritchie (1991) claims that speakers of Hausa distinguish only two sensory modalities, based on the observation that Hausa has only two perception verbs, one for vision and one

1 For more information about Avatime, see e. g., van Putten (2014) and Defina (2016a).

2 I focus specifically on how people talk about perception as non-controlled experience (as expressed by e.g., English see and hear). Verbs and constructions that refer to perception as a controlled activity (similar to, for instance, English look and listen) will briefly be discussed in Section 3.1. See also Viberg (1983) for more discussion about this distinction in general. 
for the non-visual sensory modalities. So where Viberg (1983) assumes a disconnect between the encoding of perceptual experience in verbs and people's conceptualization of the senses, these anthropological studies assume a direct link.

For the case of Avatime, which, like Hausa, has one verb for vision and one for the other sensory modalities, this means that different predictions could be made. One, assuming a direct link between perception verbs and conceptualization, is that the Avatime non-vision verb corresponds to a holistic 'non-visual' sensory modality. The other, assuming a complete separation of verbal encoding and conceptualization, is that the Avatime verb is polysemous with four separate senses ('hear', 'feel', 'taste' and 'smell'). Alternatives in between these two extremes are also possible. The current paper investigates which of these predictions holds true.

The second aspect of the language of perception mentioned above is the additional meanings of perception verbs outside the domain of perception. This topic was put on the agenda by Sweetser (1990), who observed links between particular sensory modalities and particular meanings in the domain of cognition in a number of Indo-European languages. Sweetser (1990) explains these links by referring to specific properties of our sensory modalities that can be mapped onto cognitive processes. She notes that vision is connected to the intellect, with vision verbs coming to mean 'know' and 'understand'. This can be explained by several aspects of vision: (i) vision is the main sensory modality by which we acquire objective knowledge about the world (ii) we can focus our vision on different elements of the environment, just like we can focus on different problems with our minds, (iii) vision is a distant sense, just like objective knowledge is considered distant and impersonal, and (iv) we assume that what different people see is the same and therefore knowledge acquired by vision is objective. Hearing, being the main way in which most people perceive language, is linked to the reception of speech, with meanings such as 'obey' and 'understand'. Feeling and tasting are linked to more subjective notions such as emotion, personal preference and opinion, because they are personal and proximal senses.

Further research on a more diverse variety of languages has shown that the links between perception and cognition are more culturally variable than Sweetser (1990) envisaged. In a number of languages around the world, hearing is the sensory modality most closely connected to knowledge and the intellect (Aikhenvald and Storch 2013; Evans and Wilkins 2000; Ibarretxe-Antuñano 2008; Vanhove 2008). Evans and Wilkins (2000) speculate that, for Australian languages, this could be related to the culture of the speakers, in which hearing is considered a more focused activity and more important for the acquisition of knowledge. These further findings are compatible with the idea of a potentially universal general link between perception and cognition, with culture-specific 
mappings from particular sensory modalities to particular cognitive notions (Ibarretxe-Antuñano 2008; San Roque et al. 2018).

Coming back to Avatime, what kinds of non-perception meanings can we expect for the two perception verbs mò 'see' and nu 'hear/feel/taste/smell' and what can these tell us about the speakers' conceptualization of perception? Given that both vision and hearing have been attested to be linked to objective knowledge, both Avatime perception verbs could potentially have additional meanings in this domain. We can also expect the verb $n u$ to be used in the domain of emotions and personal preference, given that it encompasses the personal and proximal notions of 'feel' and 'taste'. Previous research into other general nonvision verbs in Romance languages (Enghels and Jansegers 2013; Guerrero and Cruz Domínguez 2017) and Lussese (Bantu) (Thanassoula 2013, 2016) has shown these verbs to have a wide variety of non-perception meanings, referring to beliefs, emotions, opinions, knowledge and understanding. This could indicate that the domain of cognition is linked more strongly to the non-visual senses than to vision in these languages. Whether this is also the case for Avatime will be investigated in this paper.

In order to shed light on the issues mentioned above, a detailed analysis of the grammatical properties, semantics and discourse usage of the Avatime perception verbs is necessary. More specifically, the following questions will be addressed.

1. How is the non-vision verb nu used within the grammar of the language? Do the grammatical constructions in which it occurs disambiguate the different interpretations of this verb?

2. Is the non-vision verb $n u$ polysemous or semantically general and do its interpretations map onto the traditional five sensory modalities?

3. What interpretations outside the domain of perception do the vision verb mj and the non-vision verb nu have? What can these tell us about how perception is conceptualized?

4. How do people use the two verbs to talk about perception in discourse? To what extent are they used to refer to perception in general and to perception with specific sensory modalities?

These questions will be addressed in the next four sections, after a discussion of the method and data.

\subsection{Method and data}

The research questions mentioned above will be addressed using two different methods: translation of English sentences to Avatime and the analysis of more spontaneous discourse. 
For the translation task, I largely followed the Grammar of Perception Questionnaire (Norcliffe et al. 2010). This questionnaire was developed to investigate how meaning is packaged into grammatical constructions in perception event descriptions and what differences there are in the grammatical means used for the different sensory modalities. It consists of 60 main scenarios and 63 optional additional scenarios that tap into various semantic aspects of perception events that may be relevant for grammatical encoding. Each scenario consists of a context part and a target part that is to be translated by the language consultant. An example can be seen in (1), where the part in bold is the target part and the context makes sure that the English word taste is interpreted correctly (in this case as referring to active tasting rather than the passive experience of taste).

(1) Yesterday I made a pot of tea for my father. I wanted to know if it was sweet enough. Before I gave it to him, I tasted it.

(Norcliffe et al. 2010: 10)

All main scenarios and some of the optional scenarios were translated by six speakers of Avatime. ${ }^{3}$ A number of additional scenarios relevant to Avatime were developed and translated by at least two consultants each.

The translation of questionnaire scenarios was complemented by the study of perception verbs in spontaneous discourse. The corpus of discourse used for this study consists of transcribed and translated recordings collected over the course of several field trips to the Avatime area between 2008 and 2016 by Rebecca Defina and myself. The genres included in the corpus are: elicited narratives (based on pictures or videos), traditional narratives, life stories, descriptions of procedures, interviews, focus group discussions, public meetings and everyday conversations. ${ }^{4}$ There are a total of 76 recordings that contain the verbs mò or $n u$. The total length of these recordings together is over 15 hours. The corpus contains a total of 223 occurrences of $n u$ 'hear, perceive' and 839 occurrences of $m \grave{\jmath}$ 'see'. All occurrences of $n u$ and approximately $70 \%$ of the occurrences of mì were coded for their meaning in context, the type of object they occur with and the grammatical construction they occur in. ${ }^{5}$

3 Many thanks to Rebecca Defina who recorded and transcribed the first four speakers and carried out a first analysis of the data.

4 All recordings up to 2013 are archived at The Language Archive at the MPI for Psycholinguistics, Nijmegen: https://hdl.handle.net/1839/00-0000-0000-0016-AA18-E. The 2016 recordings can be found in the archive of the Lund University Humanities Lab, see https://hdl.handle.net/10050/00-0000-0000-0003-CEDE-3@view. The examples in this paper are followed by the file names of the recordings they are taken from and by which they can be found in the archives.

5 The remaining 30\% of mò cases was eyeballed and did not reveal more diversity than was already present in the coded cases. 
Whereas the translation data provides an overview of the grammatical constructions that can be used for situations which may be rare in spontaneous discourse, the corpus data adds information on both frequency and additional uses of verbs that may not have been covered by the preconceived situations presented in the questionnaire. Together, the two methods allow for a comprehensive and detailed picture of the grammar and use of perception verbs in Avatime.

\section{Grammatical properties of the verb $n u$}

The verb nu refers to perception with the four non-visual sensory modalities: hearing, feeling by touch, tasting and smelling. This wide range of meanings raises the question of how and to what extent speakers of Avatime disambiguate between these sensory modalities. Ritchie (1991) suggests that speakers of Hausa, which has a similar non-visual perception verb, distinguish only two sensory modalities: vision and non-vision. To find out whether this could be the case for Avatime, too, it is necessary to look beyond the meanings of the verb nu in isolation and to investigate the grammatical constructions in which the verb occurs. This is what I will do in the present section, starting with the cases where nu occurs with an object of perception (Section 2.1), followed by constructions with a subordinate clause (Section 2.2).

\subsection{Nu with a perception object}

Unlike English, which allows any noun phrase as the object of its perception verbs, the Avatime verb nu imposes a semantic restriction on its objects. It can only take objects which refer to an abstract perceptual signal. These are nouns such as òzi 'noise', j̀dzị 'song', j̀fụ 'scent' and kuhuhu 'heat'. Examples of nu with a noun referring to such a perceptual signal are shown in (2) and (3). ${ }^{6}$ Nouns referring to other types of referents (e.g., banùvj̀ 'children', òhui 'car', séfofo 'flower' and òni 'soup') cannot directly occur as the objects of $n u$, as illustrated in (4) and (5).

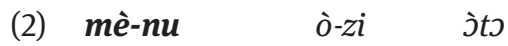

1s.PFV-perceive C2s-noise INDF

'I heard a noise.'

(GoP_100805_DQ)

6 In the examples in this paper, I gloss nu as 'perceive'. This is a practical decision and does not necessarily reflect a semantic analysis of the verb. A semantic analysis will be proposed in Section 3. 
(3) $\boldsymbol{m e ̀ - n u} \grave{j}-f \grave{u}=n \boldsymbol{\jmath}$

1s.PFV-perceive $\mathrm{c} 2 \mathrm{~s}$-scent $=\mathrm{DEF}$

'I smelled the scent.'

(elic-gop_160713_PKD)

(4) * ${ }^{\text {mè-nu }}$ ò-hui=lò

1s.PFV-perceive $\mathrm{C} 2 \mathrm{~s}$-car=DEF

intended: 'I heard/perceived the car.'

(elic-gop_160802_AB)

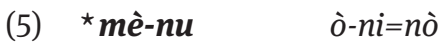

1s.PFV-perceive c2s-soup=DEF

intended: 'I smelled/tasted/perceived the soup.'

(elic-ideo-gop-landscape_160802_SO)

If one wants to talk about non-visually perceiving concrete referents such as a car or soup, there are two possible constructions. The first is to combine this concrete referent with the relevant perceptual signal in a possessive construction. This complex NP can then be used as the object of the verb nu. This strategy is conventionally used for the sensory modalities of smell and taste, using the nouns j̀fụ 'scent' and òle 'taste' respectively. An example can be seen in (6). Here, the NP kùkwiye 'the pepper' refers to a concrete perceived referent and is combined with the NP òlelò 'the taste', which refers to the perceptual signal. Possessive constructions in Avatime consist of juxtaposition with possessorpossessum word order, so the complex NP kùkwiye òlelò means 'the taste of the pepper'.

(6) kòfi e-nu kùkwi=ye ò-le=lò ní ò-ni=no mè

Kofi C1s.PFV-perceive pepper=DEF C2s-taste=DEF LOC C2s-soup=DEF inside

'Kofi tasted the pepper (perceived the taste of the pepper) in the soup.'

(GoP_100706_SO)

The second type of construction for talking about a concrete perceived referent uses the postposition ònu. This construction is used mostly for the sensory modalities of hearing and touch, as exemplified in (7) and (8).
(7) mè-nu
ò-hui=lò
ònu
1s.PFV-perceive c2s-car=DEF POSTP
'I heard the car.'
(elic-gop-landscape_160802_PKD) 
(8) mè-nu lị-wj̀ ylịnị=ne ònu

1s.PFV-perceive C3s-wind cold=DEF POSTP

'I felt the cold wind.'

(elic-gop_160802_AB)

The $n u+$ ònu construction can also be used for smell, but this is rare. One example can be seen in (9). Whether or not the construction can also be used for the sensory modality of taste needs further investigation, but there are no cases of this in the questionnaire or corpus data.

(9) mó-nu kùkwi=ye ònu pj̀ e-yeyi mè ní

1s.PFV.NEG-perceive pepper=DEF POSTP but c1s-hurt 1s LOC

ò-nugu=lo mè

c2s-mouth=DEF inside

'I did not smell the pepper, but I tasted it (literally: it hurt me in the mouth).' (elic-gop_160713_PKD)

The postposition ònu is also used for spatial expressions, to indicate a location at the opening or entrance of a reference object. An example of this usage can be seen in (10).

$$
\begin{aligned}
& k a-d r u ̣ i=a \quad k a-d i \quad \text { ní li-gblè=le ònu } \\
& \text { c6s-dog=DEF c6s.PFV-sit LOC C3s-cage=DEF POSTP }
\end{aligned}
$$

'The dog is sitting in front of / by the entrance of the cage.'

(RS0808191)

It is unclear how the spatial meaning of ònu is related to its meaning in perception constructions. A possible route is via sentences such as (11). Here, the postposition ònu indicates a metaphorical location - the source of information. This is similar to the use of the English spatial preposition from. However, unlike English from, the postposition ònu is not normally used in spatial expressions to indicate a source of motion, so there is no direct link between the spatial and perception usages of ònu. ${ }^{7}$

7 The postposition ònu has clear similarities to the verb $n u$ as well. It may be that the homophony with the spatial postposition is accidental and that onu in this construction is derived from the verb $n u$. Verbs can get an $o$ - prefix when semi-nominalized in a non-finite complement construction (Defina 2016b). However, perception verbs do not occur with non-finite complements, so this seems an unlikely path of development. 


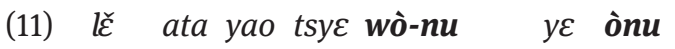
and Ata Yao too 2s.PFV-hear c1s POSTP

'And Ata Yao, did you hear from / about him (whether he will come to the festival) ?'

(conv-ablorme_100715_SO-AS)

Based on the data presented so far, we can conclude that some of the meanings of the verb nu can be disambiguated by the grammatical construction in which the verb occurs. To talk about taste and smell, the noun phrase describing the perceived referent is usually combined with the nouns òle 'taste' and j̀fù 'scent', keeping these two sensory modalities apart. Hearing and feeling by touch, on the other hand, can only be referred to with a more general construction. This raises the question if and how people distinguish hearing and feeling if they have to. To investigate this, I asked four consultants to translate sentences such as 'he did not hear it but he felt it'. An example of a response can be seen in (12). Here, the speaker uses the $n u+$ ònu construction for both sensory modalities, but modifies the clause referring to feeling with the adverbial phrase ni kisudzyac su 'on the skin'.

(12) Preceding context: 'I was almost asleep when suddenly a cat jumped onto my bed.'

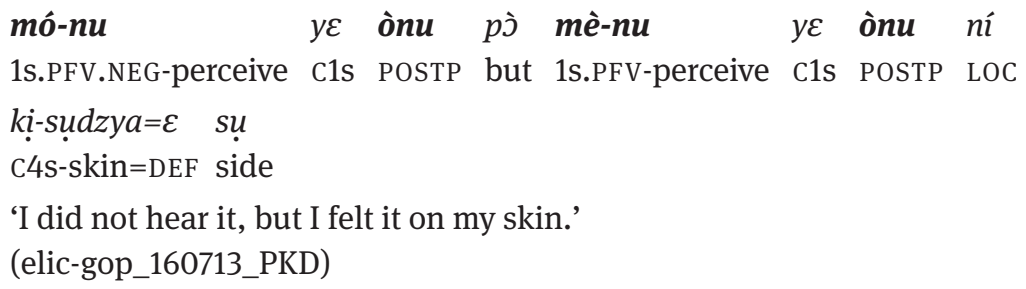

In all responses, the part of the sentence that refers to hearing was expressed using the verb $n u$ with or without the postposition ònu (depending on the object of the verb). For the part of the sentence that refers to feeling, several ad hoc strategies were used, such as the phrase ‘on the skin' as in (12), a paraphrase such as 'it touched me' or 'it moved me', the verb mò 'see' (see also Section 5.2), or the English verb feel. This was independent of the order in which the two meanings occurred in the prompt, i. e., the same results hold true for sentences such as 'I did not feel it, but I heard it'. An example of a response with this order can be seen in example (14) in the next section.

These results show that people can disambiguate hearing and feeling when necessary, but there is no conventional way of doing so. In particular, there is no conventional way to unambiguously refer to feeling by touch. There does not seem 
to be a noun for this sensory modality (analogous to j̀fu 'scent' and òle 'taste') and there is no other clearly preferred strategy for referring to it. The fact that all consultants consistently used nu (+ ònu) to refer to hearing and various different strategies to refer to feeling also provides evidence for hearing as the default interpretation of $n u$. This will be discussed further in Section 3.3.

\subsection{Nu with a subordinate clause}

There are two different subordinating constructions with $\mathrm{nu}$. One is constructed with the relativizer gi and is used for direct or immediate perception, where the speaker makes clear that he or she witnessed the event described in the subordinate clause (see e.g., Dik and Hengeveld 1991; Noonan 1985). An example can be seen in (13).

$\boldsymbol{e}$-nu ba-ỵinà gì $b \varepsilon$-gá
C1s.PFV-perceive c1p-ants REL C1p.PFV-move:LOC C3p-face=DEF inside
'He felt ants walking on his face.'
(GoP_100805_DQ)

This construction can be used for both hearing and feeling. It is not used in my data to refer to smelling or tasting, but further research is necessary to establish whether or not this is possible. The construction does not disambiguate between sensory modalities.

The other type of subordinating construction is the use of a complement clause with the complementizer si. In the available data, $n u$ with a complement clause is only used to refer to hearing, but further research is needed to establish whether or not it can refer to other sensory modalities as well. An example can be seen in (14). Like Example (13) above, this is a case of direct perception.
edzenia j́-tù

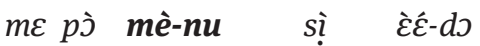
rain C1s.PFV.NEG-hit 1s but 1s.PFV-hear COMP C1s.PROG-fall

'The rain did not touch me, but I heard that it was raining (prompt: I did not feel the rain, but I heard it).'

(elic-gop_160709_AB)

Examples such as (14), where a complement clause refers to direct perception, are not very common in the corpus. More commonly, $n u$ with a complement clause is used with a 'hearsay' interpretation. In these cases, the speaker uses nu to indicate that she did not directly witness the event described, but that the information was obtained from another person. An example can be seen in (15). 
(15) mè-nu sị be-tá-bịte páti j-tว ní ke-pe bìdi=a 1s.PFV-hear COMP C1p-INT-do party c1s-INDF LOC c6s-house big=DEF $m \grave{\varepsilon}$ inside 'I heard that there will be a party in the big house.' (kadzidzia_110409_AB_1)

\subsection{How many sensory modalities?}

In this section I have described the grammatical properties of the verb $n u$. At the beginning of this section, I asked the question to what extent the grammatical constructions in which nu occurs disambiguate its meaning. I have shown that they often do: when $n u$ refers to smelling, it usually occurs in a construction with j̀ù 'scent' and when it refers to tasting with òle 'taste'. This means that the linguistic data does not provide evidence for the hypothesis that speakers of Avatime distinguish only two sensory modalities. Even though the perception verbs mò and nu make only a two-way distinction, distinctions between other sensory modalities are made by other elements in the grammatical construction. However, the data does not support a perfect mapping onto the traditional five-senses system either, given that the notions of hearing and feeling are not conventionally disambiguated. How this may relate to the conceptualization of sensory perception will be discussed further in Sections 3.3 and 6.

\section{The meanings of $n u$}

This section discusses the different semantic interpretations of $n u$ and addresses the question of whether $n u$ has one general perception meaning (e.g., 'perceive non-visually') or several more specific perception senses (e. g., 'hear', 'feel', 'taste' and 'smell'). I first give an overview of the various semantic interpretations of $n u$ both within the domain of perception (Section 3.1) and outside it (Section 3.2) and then discuss the issue of whether $n u$ is polysemous or has a general meaning (Section 3.3).

\subsection{Perception meanings}

The interpretations of nu described in Section 2, 'hear', 'feel', 'taste' and 'smell', all refer to non-controlled perception events, in which a perceiver passively experiences a stimulus. The current section discusses to what extent nu can 
be used for other types of perception events. Verbs referring to non-controlled perception events, also called experience verbs, can be distinguished from activity verbs, which refer to intentionally controlled events (Viberg 1983). Examples of activity verbs are for instance English look at and listen. There is not always a lexical distinction between non-controlled experiences and controlled activities: the English verbs feel, taste and smell can refer to both controlled and non-controlled events and there are many languages in which the distinction is not made for any of the sensory modalities (see e. g., Aikhenvald and Storch 2013; Evans and Wilkins 2000).

So can Avatime $n u$ be used for controlled perception activities? This depends on the sensory modality referred to. $\mathrm{Nu}$ cannot be used for active feel, taste and smell. These are referred to with serial verb constructions. An example can be seen in (16), where the verb gboni denotes the activity of getting into contact with something and the visual activity verb di 'look' adds the semantics of controlled perception.
(16) mà-gbonì be di
1s.PFV-touch c4p look
'I felt it (to find out how soft it was).'
(GoP_100809_AB)

The only controlled perception interpretation that $n u$ can have is auditory ('listen'). An example can be seen in (17).
nu li-bo=lè gì èé-do=e
perceive C3s-word=DEF REL C1s.PROG-Say=CM
'Listen to what he his saying!'
(elic-gop-landscape_160802_PKD)

It is not always straightforward whether to translate an instance of $n u$ as 'hear' or 'listen'. Sometimes, the context will force a particular translation, i. e., 'listen' when imperative, as in (17). Most of the time, whether or not a hearing event is controlled or non-controlled simply seems to be left unspecified (for a similar observation, see Aikhenvald and Storch [2013: 19-20]).

If people need to unambiguously refer to a controlled auditory event, they can use a more specific construction: the phrase tã kutu, literally 'eat/chew ear'. An example, in which the expression is shortened to tã tu, can be seen in (18). The phrase $t \tilde{a}(k u) t u$ is common in the questionnaire translations, which contain context in which the specific reference to controlled perception is made relevant. In the corpus of spontaneous discourse, controlled events are more often referred to with $n u$ and $t \tilde{a}(k u) t u$ is rare. 


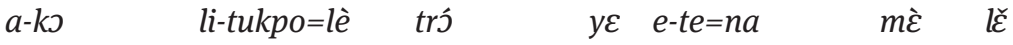

$$
\begin{aligned}
& \text { C1s.PFV-take C3s-head=DEF put.on:LOC C1s C3p-chest=DEF inside and } \\
& \text { a-tã } \quad \boldsymbol{t u}=i
\end{aligned}
$$

'She put her head on his chest and listened (to his heart).'

(GoP_100805_DQ)

Another distinction that can be made within perception verbs is between verbs that take the experiencer as their subject and verbs that focus on the source of perception and some quality ascribed to this source. The latter have been called copulative verbs or source-based verbs (Viberg 1983). Examples are English look as in it looks beautiful and sound as in it sounds loud. The Avatime verb nu is not used on its own as a source-based verb, but it occurs in a source-based construction that is used to refer to positively-valued perception events. This construction looks like a serial verb construction with a first verb pe and as the second verb either $n u$ or the verb $d i$ 'look'. The first verb pe, however, occurs only in this construction and is never used as a verb on its own. Examples can be seen in (19) and (20).

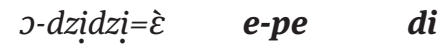

$$
\begin{aligned}
& \text { C1s-moon=DEF C1s.PFV-pe look } \\
& \text { 'The moon looks beautiful.' } \\
& \text { (GoP_100805_DQ) }
\end{aligned}
$$

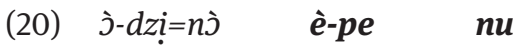

$$
\begin{aligned}
& \text { C2s-song=DEF C2s.PFV-pe perceive } \\
& \text { 'The song sounds good.' } \\
& \text { (GoP_100809_MM) }
\end{aligned}
$$

The $p e+n u$ combination is only used for hearing and not for feeling, tasting or smelling.

In this section we have seen that $n u$ can be used on its own for controlled perception and as part of a construction for positively-valued source-based perception. In both cases it is only used to refer to hearing and not to touch, taste or smell. This indicates that hearing is more central to the meaning of $n u$ than the other sensory modalities. I come back to this in Section 3.3.

\subsection{Non-perception meanings}

There are three non-perception interpretations of $n u$ that occur in the corpus. The first is 'heed' or 'obey'. An example can be seen in (21), where the person spoken to likely did perceive what the parents said (otherwise she would not have been able to refuse), but she did not do as they told her. 
(21) wo-kà nì wo-ne be-do sị wo xé wò-gbe, 2s.Poss-father and 2s.Poss-mother c1p.PFV-say say $2 \mathrm{p}$ and 2s.PFV-refuse wó-nu

2s.PFV.NEG-perceive

'Your father and mother told you and you refused, you didn't listen.' (kadzidzia_110406_AuA)

The second type of non-perception meaning that nu may have is 'understand/know a language', as in (22). In this case, the object of $n u$ is either the word sìyà 'language' or a language name.
bá-lí-nu
blo sì-yà
C1p.NEG-PROG.NEG-perceive 1p c7-language
'They don't speak/understand our language'
(Avatime-history_110905_BB)

Thirdly, nu can also mean 'understand' more generally. In this case its object is usually followed by a postposition. This can be either ese 'under' or $m \dot{\varepsilon}$ 'inside'. An example of the latter can be seen in (23). There are also a few cases where $n u$ is used without any postposition but is still interpreted as 'understand'. An example can be seen in (24).

(23) wò-nu be mغ

2s.PFV-perceive c4p inside

'Did you understand?'

(famprob_110316_MM-AlA)

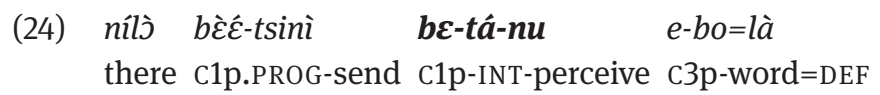

'Where they are sending this (recording), will they understand it (what is being said)?

(conv-rice_110411_3-2)

All three non-perceptual interpretations of $n u$ are related to the sensory modality of hearing. They are very similar to meaning extensions attested for verbs of auditory perception crosslinguistically (Evans and Wilkins 2000; Vanhove 2008) and in line with Sweetser's (1990) prediction that hearing verbs will extend their meaning to notions related to linguistic communication (if we assume that a more general notion of understanding may evolve out of the more specific notion of understanding spoken language mentioned by Sweetser).

Perhaps unexpectedly, the verb $n u$ does not have any non-perception interpretations that are related to sensory modalities other than hearing. As discussed 
in Section 1.1, the sensory modalities of touch and taste are often linked to subjective notions of cognition. This is especially true for verbs like English 'feel', which are more frequently used for mental states, emotions or general physical wellbeing than they are for feeling by touch (Sweetser 1990; Viberg 2008). Avatime $n u$, despite its use for feeling by touch, does not have any of these interpretations. To talk about emotions, various other constructions can be used, one of which uses the verb mò 'see', as discussed in Section 4.2. General wellbeing is expressed with a copula construction as in (25).

$$
\begin{aligned}
& \text { o-le mò } \\
& \text { C1s.PFV-be.at good } \\
& \text { 'She is feeling good.' } \\
& \text { (conv-hair_100805_CA-AB) }
\end{aligned}
$$

The fact that the non-perception interpretations of $n u$ are related to the auditory sensory modality, together with the fact that nu does not have the typical nonperception interpretations of 'feel' verbs, provides further evidence for a basic auditory interpretation of $n u$.

\subsection{Nu as both general and polysemous}

This section addresses two related questions. First, is the verb nu polysemous with separate senses referring to separate sensory modalities, or can it be considered as having a single general perception meaning (i.e., 'perceive non-visually'). Second, is there one sense or interpretation of the verb that is more central than the others?

Starting with the second question, there is some evidence that shows that the verb $n u$ has a central auditory interpretation. First, the auditory interpretation is the default when people hear the verb $n u$ in a sentence without any context. Second, as was shown in Section 2.1, the auditory interpretation is also treated as default when people are asked to translate sentences that contrast hearing and feeling. Finally, as was shown in Section 3.2, all non-perception meanings of $n u$ are related to auditory perception. These pieces of evidence show that $n u$ is at its core a verb of hearing and the other interpretations are less central. ${ }^{8}$

8 The auditory interpretation is also the most frequent in the corpus. Out of the 165 cases of $n u$ with a perception meaning, 152 refer to hearing. This could be considered additional evidence for its status as the central meaning of the verb. However, it is not necessarily the case that the most frequent meaning is also central. This is shown, for instance, by Strik Lievers (2007) for the Italian perception verb sentire, which occurs most frequently in reference to hearing but at its core has a general perception meaning. 
The hearing interpretation is not only central to the meaning of the verb, but is also best analyzed as a separate sense. This is shown by applying the so-called definitional test (see e.g., Riemer 2005). The definitional test assumes that if a word has a general meaning, there should be a definition that includes all the interpretations of the word and at the same time excludes interpretations that the word does not have. At first sight, it seems that there is such a single definition for all perception interpretations of $n u$, which would be something like 'perceive non-visually'. However, if we study the semantics of $n u$ in more detail, there is a problem with this definition: the auditory interpretation of nu can occur in more contexts than the 'smell', 'taste' and 'feel' interpretations. This was shown in Section 3.1. Firstly, nu can refer to controlled auditory perception ('listen') but not to controlled olfactory, gustatory or tactile perception. Secondly, when $n u$ is used in the $p e+n u$ construction, it refers to source-based, positively-valued auditory perception events ('it sounds good') and cannot refer to sensory modalities other than hearing. This means that a definition of the perception meaning of $n u$ as 'non-controlled non-visual perception' is too narrow: it does not include the controlled and source-based auditory interpretations. On the other hand, if $n u$ is underspecified for the type of perception event construal (controlled or noncontrolled, experiencer-based or source-based), then we would expect it to refer to controlled feeling, tasting and smelling and there is no explanation for why it only refers to audition in the $p e+n u$ construction. Therefore, the auditory perception interpretation is best analyzed as a separate sense. The broad range of applications of this sense compared to the other sensory modalities is also additional evidence for its status as the central meaning of $n u$.

What about the other perception interpretations? The fact that 'hear/listen' is analyzed as a separate sense, does not necessarily mean that 'smell', 'taste' and 'feel' should also each be separate senses of the verb. They might still be collapsed under a more general 'non-visual perception' sense. The definitional test shows that such a general interpretation is possible: a definition as 'controlled non-visual perception' covers all three interpretations and does not include interpretations that the verb does not have. ${ }^{9}$ Additional evidence for such a general perception sense comes from the constructions in which the 'smell' and 'taste' interpretations arise. If the interpretation of a word in a particular construction can be predicted based on the other elements in the construction, this shows that a general meaning is possible (cf. e.g., Croft's [1998] pragmatic model and Tyler and Evans's [2001] criterion of context-independent occurrences). As was shown in Section 2.1, the 'smell' and 'taste' interpretations almost always occur when

9 It does also include the controlled auditory interpretation, so the two senses overlap to some extent, but this is not a problem for the analysis. 
$n u$ is used with the nouns j̀ù̀ 'scent' and òle 'taste'. Given that the information about the specific sensory modality that $n u$ refers to is present in other elements of the construction, separate lexical entries for $n u$ 'taste' and $n u$ 'smell' are not necessary.

What about 'feel'? The 'feel' interpretation does not arise from the combination of $n u$ with other lexical items and only becomes apparent through context. This could be taken as an indication that 'feel' is a separate sense of the verb. However, it could also be the case that the concept of 'feeling by touch' is not lexicalized in Avatime at all and that the diverse sensations that are usually considered to belong to the sensory modality of touch are simply talked about as instances of (non-visual) perception more generally. The latter seems to be a more attractive analysis than the former, given that the sensory modality of touch is notoriously difficult to define and includes many sensations that do not appear to have anything in common, such as perceiving texture, weight, temperature and pain (for discussion of this issue, see e. g., Fulkerson 2015; Macpherson 2011; Sorabji 1971; de Vignemont and Massin 2015). The only proposed definition of touch that includes all these different types of perception is one that defines it as perception with the whole body, or more precisely, perception without a localized sense organ (Sorabji 1971). Unlike vision, hearing, taste and smell, touch is not associated with a particular organ. One might think of the skin, but we do not need the skin to feel touch (e. g., when we touch our teeth), and some sensations, such as weight, are not perceived with the skin at all. This definition basically considers touch as a catch-all category: all types of perception that do not involve the other sense organs. Given that we already had a reason to suggest a sense of $n u$ that includes all non-visual types of perception, it seems unnecessary to consider an additional sense for sensations that are also not hearing, smell or taste.

The evidence presented so far for a general 'non-visual perception' sense of nu needs a disclaimer. As has been argued many times, there does not seem to be a single principled way to determine if different semantic interpretations of a word should be regarded as separate senses or as contextually derived meanings (see e. g., Geeraerts 1993; Riemer 2005; Tuggy 1993). In fact, linguistic evidence alone may never be enough to decide about the mental representations of words (Croft 1998; Sandra 1998). Given that mental representations can be redundant, evidence for a general meaning can never exclude the possibility of polysemy: even if the meaning of a word is always predictable from the construction, it may still be specified in the lexicon as well. This does not pose a big problem for the current investigation. My main aim of presenting the evidence for a general 'non-visual perception' sense (in addition to the specific auditory sense) is to show that it is not necessary to propose separate senses referring to tasting, smelling and feeling and that it is possible to account for these interpretations with a general sense. 
This allows for an account that does not rely on the "Western" five-senses model. To what extent the semantic distinctions proposed in this section map onto the senses that are culturally distinguished and considered important in Avatime will need further anthropological and psycholinguistic investigation.

Taking stock of the evidence provided in this section, a likely analysis is as follows. The verb $n u$ has a central sense referring to auditory perception, which can be either controlled or non-controlled and which can figure in a construction with pe to refer to source-based positively valued perception. In addition it has a more general perception sense that refers to controlled non-visual perception. To talk about tasting and smelling, the verb is used in this second sense and the sensory modality can be specified further by using a construction with a noun referring to the sensory modality. The sensory modality of touch can be considered as a notion that is not part of the semantics underlying the Avatime verb $n u$ and Avatime can be considered not to have a verb or conventionalized construction that specifically refers to non-controlled perception through touch.

\section{The meanings of $m j$ 'see'}

In the previous two sections I have discussed the grammatical properties and meaning of $n u$, focusing mainly on how and to what extent the different sensory modalities are encoded in grammar and lexicon. In this section I discuss the verb $m$ '̀ 'see', focusing mainly on its interpretations outside the domain of perception.

As discussed in Section 1.1, Sweetser's (1990) embodiment approach predicts that the sensory modality of vision will be connected to objective knowledge and therefore that we might find notions related to knowing and understanding as meanings of vision verbs. As was also discussed, many languages use hearing rather than vision verbs for objective knowledge (Evans and Wilkins 2000; Vanhove 2008). Avatime uses the hearing/non-vision verb $n u$ to refer to understanding, but not to any further notions related to objective knowledge (see Section 3.2). We may therefore still expect the vision verb mò to have such meanings as well.

Another prediction made by Sweetser (1990) is that the proximal sensory modalities, especially feeling and tasting, will be connected to subjective cognitive notions such as personal preference and emotion. As was already shown in Section 3.2, the verb $n u$, which is used to refer to all the non-visual sensory modalities, including feeling and tasting, does not have this connection. One possibility is that, against Sweetser's prediction, the vision verb is used for subjective cognitive notions in Avatime. 
In the remainder of this section, I will first briefly describe how mò is used to refer to vision (Section 4.1), then I discuss its meanings outside the domain of perception (Sections 4.2 and 4.3), showing that it is used for both objective and subjective cognitive notions. I finally compare the non-perception interpretations of $m \grave{\jmath}$ to those of $n u$ and discuss the findings in relation to previous literature (Section 4.4).

\subsection{Mj̀ as a vision verb}

The verb mj̀ can occur either with a noun phrase object or with a subordinate clause. Example (26) shows mò with a noun phrase object. Unlike $n u$, mò can take any noun phrase as its object.
(26)

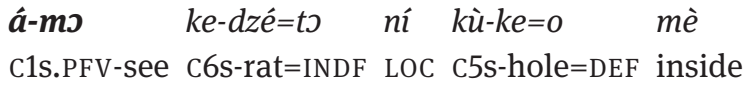
'He saw a rat in the hole.'
(frog_100719_DQ-PhA)

Like the verb $n u$ (see Section 2.2), mò can occur with two types of subordinate clause. The first type has the form of a relative clause and is used for direct or immediate perception, indicating that the perceiver has witnessed the event described in the subordinate clause. An example is shown in (27).
a-mò ba gì bèć-yà péyà C1s.PFV-see C1p REL C1p.PROG-eat pear
'He saw them eating pears.'
(pear_100630_PD-AbD)

The second and more common type is a complement clause with the complementizer sì. This construction can also be used for direct perception, as in (28), but more frequently indicates indirect perception, where the perceiver infers the information in the complement clause, based on visual evidence. The latter case is shown in (29), where the man did not actually see anybody take anything from his farm, but infers that this has happened based on the visual evidence that some of the produce of his farm is gone. 


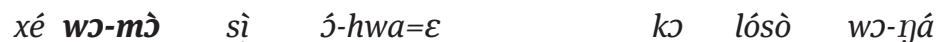

if 2s.PFV-see COMP C1s.PFV.NEG-move=CM then reason 2s.PFV-eat:LOC

$y \varepsilon a b a$

C1s on

'If you see that it (the animal you just shot) does not move, then it means you have defeated it.'

(hunting_160714_Ame)

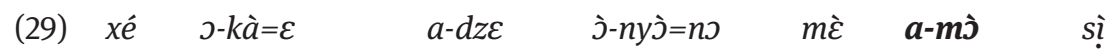
when C1s-father=DEF C1s.PFV-go C2s-farm=DEF inside C1s.PFV-see COMP

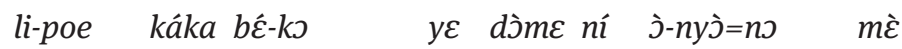
C3s-time each C1p.PFV-take C1s thing LOC C2s-farm=DEF inside 'Every time the man went to farm, he saw that things were taken from his farm.'

(kadzidzi-spider-farm_110827_ET)

In the remainder of this section, I discuss the interpretations of mò outside the domain of perception. These are related to the syntactic construction that the verb occurs in. Some non-perception meanings only occur when mò is used with a noun-phrase object and others occur mostly when it is used with a subordinate clause. I discuss these two types of interpretations in turn.

\subsection{Mj with a noun-phrase object}

When used with a noun-phrase object, mò can have three types of non-perception interpretation. The first is in the domain of social interaction, with mò meaning 'meet' or 'visit'. This is a common interpretation of vision verbs crosslinguistically (see e. g., Aikhenvald and Storch 2013; Baker 1999; Evans and Wilkins 2000; San Roque et al. 2018). An example can be seen in (30), where it is clear that the speaker does not only want to visually perceive the chief but wants to consult with him.

(30) The speaker is talking about his plans to show a video in public in the village.

mà-tá-mo $o$-kusi=è gba to kíà-bu be

1s-INT-see c1s-chief=DEF first PURP 1p.POT-remove c4p

'I am going to see the chief first before we will show it (literally: remove it).' (language-use_130810) 
The second type of non-perception interpretation that is possible when mò occurs with a noun phrase object is in the domain of possession. This interpretation is crosslinguistically unusual, but it seems to be relatively common among languages spoken in parts of Africa (Aikhenvald and Storch 2013; Ameka 2013). The verb mò can mean 'find', 'get' or 'have'. Note that Avatime does not have a verb like English have and using mò is one of two conventional ways to talk about possession. ${ }^{10}$ Examples can be seen in (31), which is a case of more literal ownership, and (32), where the concept of possession is extended to abstract properties of people.

\author{
y-á-ms acre àvitata \\ LOG-C1s.PFV-see acre thirty \\ 'He has (sees) thirty acres.' \\ (conv-greenhouse_110408_SO-ViA_2)
}

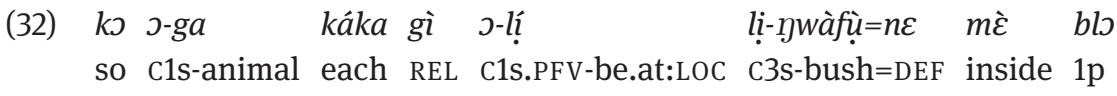

kí-mo ki-gàglà ní ye abà

1p.PFV-see C4S-strength LOC C1s on

'So all the animals in the bush, we have (see) power over them.'

(hunting_160714_Ame)

The final use of mò with a noun phrase object is to express emotions. In these cases, the object of the verb is a noun phrase referring to an emotion, such as ìsàmi 'happiness', kụ̀sụyeyì 'anger' or kụ̂ywụza 'greed/jealousy’. An example can be seen in (33).
(33)

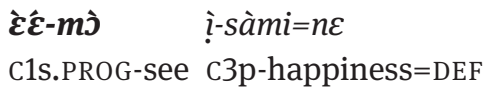
'He is happy (he sees happiness).'
(kadzidzi-chiefsson_110924_PKD)

The use of vision verbs to talk about emotions seems to be crosslinguistically rare or at least underexplored, but see Section 4.4 for more discussion. From the embodiment perspective proposed by Sweetser (1990), the connection of vision to emotion is unexpected, because vision is claimed to be related to the intellect

10 The other way to express possession is to use a locative phrase with hands, which would literally translate as 'possessum is in possessor's hands'. Both strategies are used frequently. 
and not to subjective experiences. In the next section I show more examples of the connection between vision and subjective aspects of cognition in Avatime.

\subsection{Mj̀ with a subordinate clause}

When mò occurs with a subordinate clause, it can refer to both objective knowledge and to the more subjective notions of belief and personal opinion.

The knowledge interpretation is common for vision verbs crosslinguistically (cf. e. g., Baker 1999; Evans and Wilkins 2000; Johnson 1999; Sweetser 1990) and seems a natural extension from indirect perception cases like (29), where knowledge is acquired through inference based on vision. An example of mò referring to the acquisition of knowledge without this being based on vision (only) can be seen in (34). Here, the realization of the man that he is in trouble is not just based on his visual perception of the situation he is in, but also on his interaction with the crocodile. Another example is (35), where visual perception plays no role in the insight that the history should be written down.

(34) From a folktale: a crocodile promises to carry a man across the river, but halfway tells him he will not take him any further and let him drown.

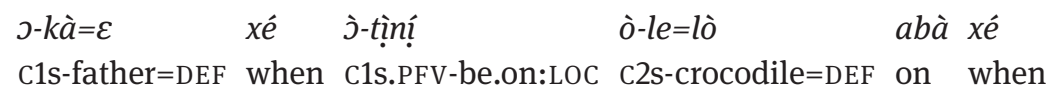

a-mò sị $\quad y$-a-xịxa lị-boboe lí-ma

C1s.PFV-see COMP LOG-C1s.PFV-be.tied C3s-nothing c3s-neg.be

'So the man sat on the crocodile and he saw/realized/knew that he was doomed, there was nothing he could do.'

(kadzidzi-crocodile_110924_PKD)

(35) lese sị kui-mò sị li-le sị à-mu=nà history, because 1p.PFV-see COMP C3s.PFV-be.at COMP C3p-rice=DEF history

ku-te ku-nwlimi $\varepsilon$-kpe ní j̀-kúts

1p.SBJV-know 1p.SBJV-write svM-put.in LOC c2s-place:INDF

'Because we see/realize that we should know the history of the rice (cultivation) and write it down somewhere.'

(chiefs-meeting_100619_03)

The subjective interpretations of vision verbs have been less frequently explored in the literature (but see Section 4.4 for more discussion). An example of mj referring to a personal point of view is line 2 of (36), where speaker B uses mj 
to give her opinion about what she thinks is happening in the picture they are describing.

(36) Two speakers describe what they see in a picture.

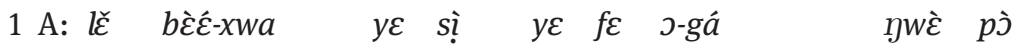
and C1p.PROG-call C1s COMP C1s too C1s.SBJV-move drink but

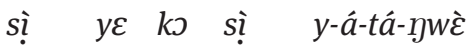

QUOT C1s CTR QUOT LOG-C1s.NEG-INT-drink

'And they were calling him to come and drink too, but as for him, he said he will not drink.'

2 B: $\boldsymbol{m a} \boldsymbol{a}-\boldsymbol{m} \grave{\jmath} \quad s i ̣ \quad y \varepsilon$ kJ $y \varepsilon$ lị-gbazèzè=ne li-má 1s.PFV-see COMP C1s CTR C1s C3s-character=DEF C3s.NEG-not.be te losòe

like.that reason

'I think (see) that as for him, his character is not like that, that's why.' (famprob_110401_MeD-BeK_describe)

Another example is (37). Here, in line 5, speaker B uses mò to indicate that it is her personal belief that the reason why the woman under discussion washed her t-shirt is that she wore it. She has not actually seen the woman wear the t-shirt. The latter is clear from line 2, in which she says she does not understand why the woman should wash her t-shirt.

(37) Speaker B is talking about a woman who did not wear her new group t-shirt for a group picture because she had just washed it and it had not dried. Speaker A asks a question.
1 A: egé
j-niye
e-plò
what:FOC C1s-person:PROX C1s.PFV-wash

'Why should this person wash it?'

2 B: mé-te le ese

1s.PFV.NEG-know C3s under

'I don't understand.'

3 A: egé kikú ye mè

what:FOC C4S.PFV-enter:LOC C1s inside

'What entered it?' (i. e., what sort of stain got into it?)

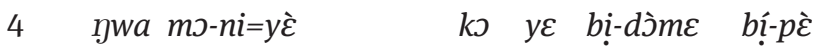

like 1s.POSS-POSSM=DEF CTR c1s c4p-thing c4p.PFV.NEG-be.good 'Like mine, it is not good.' 
5 B: a-sị bị-dj sị bi-ku ye, pj̀ ma-mò C1s.PFV-say c4p-thing:FOC say C4p.PFV-enter c1s but 1s.PFV-see sì ki-kpé $\quad a-k p \varepsilon \quad y \varepsilon$ xunys xé $\quad$-lulu COMP C4S-wear:FOC C1s.PFV-wear C1s CTR when C1s.PFV-be.dirty 'She said something entered it (before she got it) but I think/believe (see) that she wore it and it got dirty.'

(conv-funeral_100528_8-1)

Another example that shows the use of $m \grave{\text { to }}$ to indicate a personal opinion is (38). Here, $m \grave{\jmath}$ is used to indicate that the amount of money to donate is up to each person's individual choice. Note that the most natural English translation uses the perception verb feel.

(38) The speaker is describing what happens at a funeral. At some point a big bowl is put on the ground for people to put donations into.

tiasca gì wo tutग wo-mò sị wáà-kpe ní àgbe mè, amount REL 2s yourself 2s.PFV-see COMP 2s.POT-put LOC bowl inside

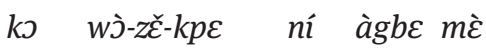

then 2s.PFV-IT-put LOC bowl inside

'The amount which you yourself feel like (see that) you will put in the bowl, you will go and put it in the bowl.'

(funerals_110822_BB)

This use of mò for subjective, personal opinions contradicts Sweetser's (1990) prediction that vision verbs only refer to objective knowledge. As was mentioned in Section 1.1, Sweetser argues that the association between vision and objective knowledge has its roots in the nature of vision itself. Because we see things from a distance, we also keep a personal distance to the knowledge gained through vision. In addition, we assume that what other people see is the same as what we see and therefore we consider the knowledge gained through vision to be objective. The Avatime data show that this is not universally true and that vision may also be conceptualized as a more private and personal sensory modality.

\subsection{Seeing, hearing and cognition}

As we have seen in the previous section, the verb mj 'see' is used with reference to objective knowledge, as well as personal opinions and beliefs. The latter, subjective, conceptualization of vision is also reflected in the use of mò to express emotions, as described in Section 4.2. It also aligns with the use of mò for possession, also discussed in Section 4.2. Ameka (2013: 238), writing about the use of 
vision verbs for possession in the Ghanaian Kwa languages Likpe and Ewe, comments that this "reflects the idea that what is in one's perceptual domain belongs to them". The idea that what I see belongs to me follows more naturally from a view of vision as private and personal than from a view of vision as distant and objective.

The use of vision verbs for subjective cognitive notions has hardly been discussed in the literature, but is not unique to Avatime. ${ }^{11}$ Vision verbs can be used for emotions in Kambaata and several other Ethiopian languages (Treis 2010) as well as in Luganda (Thanassoula 2012) and Ewe (Ameka 1990). Using the vision verb for talking about one's personal opinion can also be done in English, using phrases such as the way I see it or as I see it. A difference with Avatime is that English uses special constructions for this purpose with elements such as way, as or like, which also contribute to the subjective reading. In Avatime, the same basic complement construction is used for vision as well as for both objective and subjective cognition. Another subjective notion that is expressed with the vision verb in several languages is what San Roque et al. (2018) call subjective co-identification. This notion is also expressed with a specific construction. In English this is the construction see $X$ as $Y$, for instance $I$ never saw it as a radish (San Roque et al. 2018: 383). Finally, a quick search through RefLex, an online collection of dictionaries and word lists of African languages (Segerer and Flavier 2011-2018), also yields several cases of what seem to be subjective interpretations of vision verbs. For example, in Mano (Mande) the verb g $\overline{\tilde{\varepsilon}}$ glossed as 'voir' ('see') has an additional meaning 'penser' ('think'), which could indicate a subjective interpretation, as well as 'considérer (comme)', ('consider as') which seems to be an instance of subjective co-identification (Khachaturyan 2012). Another example is Pular (Atlantic), in which the verb yi'ugol glossed as 'voir' has the additional gloss 'penser' but also 'être de l'avis que' ('be of the opinion that') (Bah 2009). More in depth research on perception verbs in individual languages is needed to understand the variety of subjective notions that can be expressed by vision verbs, but it is clear that an account of vision as inherently linked to objective cognitive notions only cannot be upheld in the light of crosslinguistic data.

The non-vision verb nu can refer to obeying, knowing a language and understanding (see Section 3.2). This makes nu very different from general non-visual perception verbs in several other languages. French, Spanish and Italian also have general non-vision verbs, but these have various non-perception interpretations in the domains of knowledge, personal opinion and emotion (Enghels and Jansegers 2013). For instance, the Spanish verb sentir conveys "subjectivity

11 Thanks to two anonymous referees for pointing out examples of subjective uses of 'see' verbs in other languages. 
and epistemic modality: the perceiver's feelings, emotions, attitude, judgment, thoughts and viewpoints" (Guerrero and Cruz Dominguez 2017: 369). The general verb hulira in Lussese (Bantu) has a wide range of non-perception uses, related to social interaction, cognition and emotion (Thanassoula 2012, 2013). In these languages, the broad range of perception interpretations corresponds to a broad range of non-perception interpretations. This is not the case in Avatime, where the general non-visual perception verb $n u$ has a broad range of perception interpretations, but only a few meanings outside the domain of perception.

Going back to the Avatime vision verb mò, it is striking that its interpretations outside the domain of perception are very similar to those of the general perception or non-vision verbs in Romance languages and Lussese mentioned above. The interpretation of mò in the domain of emotions also shows a similarity to verbs for feeling by touch in other languages, such as English 'feel'. The verb mò thus has many of the non-perception interpretations that might have been expected for the verb $n u$. This provides evidence for the idea that there is a potentially universal link between perception and cognition, but that the connections between particular sensory modalities and particular cognitive meanings are more language specific (see also Evans and Wilkins 2000; Ibarretxe-Antuñano 2008; San Roque et al. 2018).

\section{Perception meanings in discourse}

In the previous sections, I have discussed the grammatical properties and meanings of the perception verbs nu and mò. In this Section, I explore how these verbs are used in discourse to talk about perception. The question to be answered here is to what extent these two verbs can be used as general perception verbs and what specific sensory modalities they are mostly used for. Given that one of the senses of $n u$ proposed in Section 3.3 is a general 'perceive non-visually' sense, we could expect the verb nu to be used in this general way. That is, we may expect people to talk about non-visual perception, leaving the sensory modality underspecified. The verb mò 'see' could also be expected to have more general and non-visual perception interpretations, given its wide range of non-perception meanings which correspond to meanings of more general perception verbs in other languages. In this section, I first discuss the discourse uses of $n u$ and show that, contrary to what might be expected, $n u$ is only used for modality-specific perception (Section 5.1). I then go into the use of $m$ j̀ 'see' for general and non-visual perception, and provide an explanation for why mò seems to have some of the functions in this domain that might have been expected of $n u$ (Section 5.2). 


\section{$5.1 \mathrm{Nu}$ in discourse}

As was mentioned in Section 1.2, the corpus contains 839 cases of mò and 223 cases of $n u$. The difference in number of cases is in line with the finding by San Roque et al. (2015) that people across languages talk more about vision than about the other sensory modalities. For the non-visual sensory modalities San Roque et al. find variation in which is mentioned most frequently, but in most languages hearing comes in second place and is well-ahead of touch, taste and smell. Avatime, part of San Roque et al's sample, is one of these languages. The data used for the current paper, taken from a larger corpus, confirm this picture. Out of the 165 cases of $n u$ that refer to perception events (the other 58 cases are non-perception meanings), the great majority, 152, refer to auditory perception. There are 11 cases of $n u$ referring to smell, 2 cases referring to touch and no cases referring to taste. ${ }^{12}$

The 11 cases of nu referring to smell are all marked as such by the use of the noun j̀ụ 'scent', as in example (39). This shows that even though j̀fù is not obligatory when talking about smell (see Section 2.1), there is a clear preference to use it.

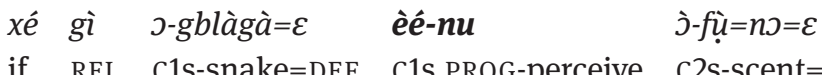

$$
\begin{aligned}
& \text { if REL C1s-snake=DEF C1s.PROG-perceive C2s-scent }=\mathrm{DEF}=\mathrm{CM} \\
& \text { á-tá-ti ponì wo tsye } \\
& \text { C1s.NEG-INT-follow add } 2 \mathrm{~s} \text { too } \\
& \text { 'If the snake smells it (perceives the scent), it will not get closer to you.' } \\
& \text { (night-hunting_110820_SO) }
\end{aligned}
$$

Of the two cases of $n u$ that refer to touch, one occurs with the object kuyeyeyi 'pain', which immediately makes the sensory modality clear. In the other case, which is shown in (40), the sensory modality is ambiguous without context. This sentence was originally translated by a language consultant as 'you will hear the sound kpu'. However, somewhat later in the discourse it becomes clear that the speaker is talking about the experience of a pregnant woman when the baby kicks or moves inside the womb, so a more appropriate translation is 'feel'. Note that this supports the analysis of hearing as the central sense of $n u$ (Section 3.3): the translator's first thought is hearing, but when context made clear this was not possible, a different interpretation was found.

12 The lack of cases of $n u$ referring to taste is not surprising, because tasting is almost by default a controlled activity. It is likely relatively rare for people to talk about tasting as a passively experienced event. Controlled tasting is not referred to with $n u$, but with a serial verb construction, combining the verbs mini 'lick' and $d i$ 'look' (see also Section 3.1). 
(40) xé bi-kpese wèé-nu bi-bịte kpu

when c4p.PFV-start 2s.PROG-perceive c4p.PFV-do ID

'When it starts, you are feeling, (it does) kpu.'

(midwifery_110901_AB)

When $n u$ refers to hearing, it most frequently occurs without any specification of the intended sensory modality and it is the context that makes the interpretation clear. An example can be seen in (41). Here, the use of $t \tilde{a} t u$ 'listen' in line 2 makes clear that nu in line 3 should be interpreted as referring to auditory sensory modality.

(41) 1 'When you've shot the gun, you wait for about two seconds.'

2 ẁ̀-tá-tã tu gba

2s.PFV-INT-chew c6s-ear first

'You will listen first.'

3 xé gì wó-nu li-boeboe ònu=i, wáà-gà

if REL 2s.PFV-NEG-hear C3s-anything POSTP=CM 2s.POT-go

'If you do not hear anything, you can go.'

(hunting_160714_Ame)

There are five cases in which the interpretation as auditory is also clear without the wider context because of the object of $n u$. One of these can be seen in (42), where the object is the noun kunugu 'talking'. There are also 22 cases of $n u$ with a subordinate clause, in which it is usually the content of the subordinate clause itself that makes the sensory modality clear, as in (43).

(42) wò-tá-nu

ku-nugu=yò ywa sì bá-náts

2s.PFV-INT-hear C5s-talking=DEF like COMP C1p-person:INDF

$b \varepsilon$-tráà

c1p.PFV-be.coming

'You will hear talking as if people are coming.'

(hunting_160714_Ame)

(43) Retelling of a cartoon in which an elephant keeps making noise by drumming and clapping and a mouse gets so tired of this that he ties his ears into a knot so that he can't hear the sound.

ó-lí-nu sị $\quad$ c̀ce-sa à-kpe-wlà tòj

C1s.NEG-PFV.NEG-perceive COMP C1s.PROG-hit C3p-put-hand anymore 'It (the mouse) does no longer hear that it (the elephant) is clapping.' (maus-drum_100709_MiA-DQ) 
There are no cases in the corpus where the general meaning of $n u$ is used to purposefully refer to perception with an unspecified sensory modality or to perception with multiple modalities at once. This shows that the broad meaning of $n u$ is not related to a more general tendency to talk about perception in a nonspecific way.

It is notable that this is not even the case in contexts in which non-visual perception is particularly relevant. This can be seen in an interview with a blind woman about how she lives her daily life. We might expect her to use nu to talk about her sensory experiences, given that these are all non-visual. However, she does not do this at all in the interview and instead uses the verb mò 'see'. An example can be seen in (44).

(44) From a description by a blind woman of how she walks from her house to the community center.

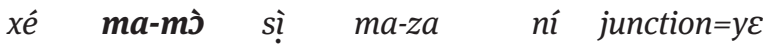
when 1s.PFV-see COMP 1s.PFV-pass LOC junction=DEF
'When I see/notice that I have passed the junction, (I will cross the road).' (being-blind_160727_EAF)

Given that the speaker in example (44) must be using her non-visual sensory modalities to sense that she has passed the junction (probably a combination of hearing and touch), it seems unexpected that she does not use the verb $n u$. In the next section I will discuss some related examples and propose an explanation.

\subsection{Mj for non-visual perception}

In the previous section, an example was shown of mò used to refer to a non-visual perception event. There are several other cases of this in the corpus. Two of these can be seen in (45) and (46).

(45) From a description by a blind woman of how she carries out tasks around the house.

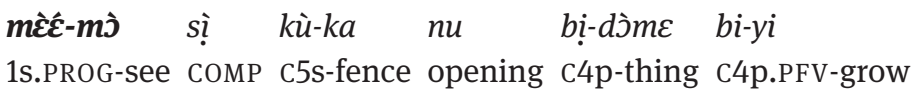

'I see/notice that the things (weeds) at the entrance of the fence have grown tall.'

(being-blind_160727_EAF) 

(46) xé gì mè-mini di=i, xé ma-mò sị kù-ms=s when REL 1s.PFV-lick look=CM when 1s.PFV-see COMP C5s-salt=DEF level=yè $\quad a-p \grave{\varepsilon}=\varepsilon$ level=DEF c1s.PFV-be.good $=\mathrm{CM}$

'When I taste it and see/find that the salt level is good (then I add okra and beans and stir it).'

(okra_AB)

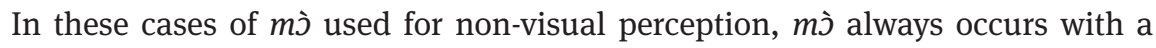
subordinate clause. This is the same grammatical construction in which mò can be interpreted as referring to the domain of cognition (Section 4.3). This connection to cognition seems to be what drives the use in non-visual perception contexts. In example (45), the speaker uses mò to refer to knowledge that she has obtained through non-visual perception, in this case touch. However, her main message is the fact that she has acquired the knowledge that the weeds have grown tall. Given that mò can be used to talk about the acquisition of knowledge more generally, it can also be used in cases where this acquisition of knowledge is based on non-visual perception. In (46), mò is used to describe a tasting event. However, the main message is that the speaker approves of the salt level. The verb mò is used here because of its more general connection to personal opinion.

In the examples above, the subordinate clauses do not describe perceptual experiences directly, but rather conclusions drawn from perceptual experiences. For the speakers who produced these utterances, the main point was not to describe a perceptual experience, but to convey a particular realization or belief. One could therefore argue that they are simply cases of the cognitive use of mo and have little to do with perception. However, there are also cases of subordinate clauses used with mò that directly describe non-visual perceptual experiences. Most of these cases refer to the sense of touch, as exemplified by (47) and (48) below. There is one case in the corpus of mò being used with an auditory experience, shown in (49).

\footnotetext{
(47) wò-tá-mò sì $\quad k u$-blo ki-balí wo abà wiii 2s-INT-see COMP C5s-cold C5s.PFV-pour:LOC 2s top ID.all.over 'You will feel (see) that the cold will come all over you.' (hunting_160714_Ame)
} 
(48) A woman is walking while carrying a load of food on her head. She does not know that there is a big snake behind her removing the things from her head one by one.

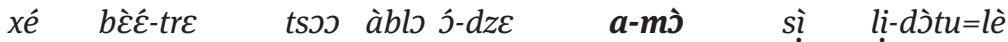
when C1p.PROG-go soon now C1s-woman C1s.PFV-see COMP C3s-load=DEF ki-fotsofotso kó lì-ku C4s-light only:FOC C3s.PROG-reach

'When they were going, soon the woman felt (saw) that the load was getting lighter and ligher.'

(kadzidzia_110406_AuA)

$\begin{array}{lllllll}\text { àblac } & \text { kịà-ze-panì } & \text { e-bó } & \text { lé-yá } & \text { te } & \text { ma-mò } & \text { sì } \\ \text { now } & 1 \text { p.POT-REC-talk } & \text { C3p-matter } & \text { PROX } & \text { like.this } & 1 \text { 1s.PFV-see } & \text { COMP }\end{array}$

$\grave{o}-z i$ to tsye e-yi ní ò-nwe=nò=e

C2s-noise INDF too C2s.PROG-sound LOC $\mathrm{c} 2 \mathrm{~s}$-outside $=\mathrm{DEF}=\mathrm{CM}$

'We will continue talking about these matters, but I hear (see) that there is a noise outside.'

(language-use_130810)

In examples (47) - (49), the speakers clearly focus on the description of a perceptual experience rather than on the cognitive implications of this experience, but the verb mò is still used. Uses such as these may indicate a further stage of semantic change of the verb mò, where cognitive interpretations based on nonvisual evidence pave the way for the interpretation of $m$ j̀ as referring to non-visual perception more directly (for a similar suggestion based on a varied sample of languages, see San Roque et al. [2018]). However, a question that arises is why mò is used at all in these cases, given that the non-vision verb $n u$ is also available. To understand this, we need to consider how nu is used with complement clauses.

As mentioned in Section 2.2, nu with a complement clause often indicates that the information in the complement clause was obtained through hearsay (see Example (15)). This means that if speakers were to use $n u$ instead of mò for examples such as (47) - (49) above, there would be a potential for misunderstanding: the addressees might interpret the information in the subordinate clause as obtained from a third party rather than through personal experience. The verb mò, because of its connection to personal opinion and belief, is then closer to the meaning the speaker wants to convey. This also explains why nu is not used in the blind woman's narrative for cases like (44) and (45). If she had used $\mathrm{nu}$, she might have given the wrong impression that she was talking about information that she 
obtained through hearsay. Her use of the verb mò makes it clear that she is talking about her personal experience.

The fact that most cases in which mò is used for non-visual experiences refer to touch and there is only one case referring to hearing is most likely related to the default hearing interpretation of $n u$. Despite the potential misunderstanding as hearsay instead of direct auditory perception, people still prefer to use $n u$ for hearing because it is so closely associated with this sensory modality. For touch, the sensory modality will have to be derived from context, irrespective of whether $n u$ or $m \grave{̀}$ is used, leading to a preference for mò in many cases.

\section{Discussion}

This paper has contributed to the ongoing debate about universals and variability in the conceptualization of sensory perception. Whereas most previous literature in this domain has taken either a comparative linguistic or an anthropological perspective, the present study has focused on the detailed grammatical and semantic analysis of a single language. This has turned out to be a fruitful approach to provide new insights in this domain.

The language discussed in this paper, Avatime, makes a two-way distinction between vision and non-vision in its perception verbs. The main question addressed is how speakers of such a language semantically encode sensory perception and what consequences this may have for the way sensory perception is conceptualized. Four specific research questions related to this main question were formulated in Section 1.1. The answers to these questions have been discussed in Sections $2-5$ and are summarized below.

1. The verb $n u$ 'hear, perceive' is used for all non-visual sensory modalities. When it is used for tasting and smelling, the grammatical construction it occurs in usually disambiguates its meaning. There are no specific conventionalized constructions that distinguish hearing and feeling.

2. Semantically, nu can be analyzed as having a central 'hear/listen' interpretation and a general 'perceive non-visually' interpretation, in addition to several non-perception senses.

3. The vision verb mò 'see' has both objective and subjective cognitive interpretations, referring to acquisition of knowledge, personal opinion, beliefs and emotion, as well as to possession and social encounters. The non-vision verb $n u$ is used for notions related to communication and understanding.

4. In discourse, people do not use $n u$ to refer to (non-visual) perception in gen-

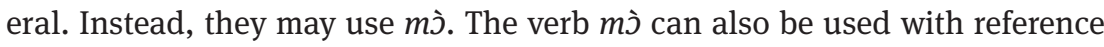
to specific non-visual modalities, especially touch. This can be explained as 
speakers avoiding the hearsay interpretation that would come with nu and preferring the personal experience connotation of $m \grave{\jmath}$.

The findings above can be related to the two aspects of the linguistic encoding of perception mentioned in Section 1.1: the grammatical encoding of sensory modalities and the links between the perception and non-perception meanings of perception verbs. I discuss the implications of the findings for each of these two aspects in turn.

With respect to the encoding of sensory modalities, Ritchie (1991) proposed that a two-way distinction between vision and non-vision in perception verbs corresponds to a cultural system in which only two sensory modalities are distinguished. This has been shown not to be the case for Avatime. Even though the Avatime verbs only distinguish between vision and non-vision, speakers of Avatime distinguish between more than two sensory modalities. The sensory modalities of taste and smell are conventionally distinguished by means of other elements in the grammatical construction. The analysis of 'hear/listen' as a central and separate sense of the verb $n u$ means that the auditory sensory modality is also encoded as a separate concept in Avatime. These findings show the importance of carrying out a detailed linguistic analysis before drawing conclusions about the potential link between verb meaning and culture.

The analysis that 'perceive non-visually' is one of the meanings of nu means that Avatime speakers must also have a general concept of non-visual perception, in addition to the more specific sensory modalities. However, the lingusitic data used for this paper do not show any evidence that this concept is an important cultural category, given that people did not use $n u$ to talk about non-vision in general. Further (psycho)linguistic and anthropological research is necessary to investigate to what extent non-visual perception is a culturally salient concept for speakers of Avatime.

I did not find evidence for a concept of experiencing something by touch (i.e., 'feeling') in Avatime. When people talk about experiencing something by touch, they use the verb $n u$, but this has a more general perception sense and by default refers to auditory perception. Unlike smelling and tasting, feeling does not have its own grammatical construction and does not have a noun to refer to it. When referring to a more complex perception event using a subordinate clause, people often use $m$ j̀ 'see' in a general perception sense to talk about feeling. The lack of a specific verb or noun or conventional construction to describe (noncontrolled) perception through touch does not necessarily mean that there is no cultural concept of a sensory modality of touch. As was mentioned in Section 3.1 (example (16)), Avatime does have a construction to refer to active exploration by touch. It also has a well-developed lexicon for talking about tactile experiences 
including many ideophones, such as dzaywudzyaywu 'rough' and vudzyuvudzyu 'hairy/bushy'. To what extent these other linguistic resources reflect some more general notion of a sensory modality of touch and if so, to what extent this notion is similar to the English notion of touch is a question for further research.

The findings related to the linguistic encoding of the sensory modalities show that the Aristotelian five senses do not necessarily correspond to the underlying concepts on which the encoding of perceptual experience in a language is based. Basing typological studies on these traditional five sensory modalities may make this system look more prevalent crosslinguistically than it really is.

The second aspect of the conceptualization of sensory perception concerns the links between the perception and non-perception interpretations of perception verbs. The Avatime findings provide evidence for the universal association of perception with cognition, but also support the evidence that the exact nature of these links may differ from language to language. Previous research has argued against the claim that vision is universally connected to knowledge by showing that there are languages in which it is hearing rather than vision that is most important in this domain (Evans and Wilkins 2000; Ibarretxe-Antuñano 2008; Vanhove 2008). Avatime shows a different, previously undocumented pattern. The Avatime vision verb mò 'see' has important links to cognition, but not only to the realm of objective knowledge, as predicted by Sweetser (1990). It also has the more subjective functions of expressing personal opinions and beliefs as well as emotion. This is despite the availability of the non-vision verb $n u$, which, based on its wide range of perception meanings and based on similar perception verbs in other languages (Enghels and Jansegers 2013; Guerrero and Cruz Domínguez 2017; Stüwe-Thanasoula 2016) could have been expected to have these subjective interpretations.

The observed crosslinguistic variation in the meanings of both vision verbs and general perception verbs shows that speakers of different languages may think about perception in different ways. Particular sensory modalities may imply distance for some and closeness for others, objectivity for some and subjectivity for others. These associations do not only show up when people use perception verbs to talk about other semantic domains. The Avatime findings show that people also have them in mind when they talk about perception itself. When talking about non-visual experiences, people may choose to use the vision verb mò, using its connotation of subjective, personal experience and avoiding the more distant hearsay interpretation that $n u$ would imply.

All in all, the linguistic encoding of perception in Avatime reveals a previously undescribed pattern of the encoding and conceptualization of the senses. This pattern enriches our knowledge of the grammar and vocabulary of perception across languages and provides new starting points for further comparative research in this domain. 
Acknowledgments: I would like to thank all the speakers of Avatime who have helped me in various ways, especially Samuel Oboni, Prosper Dugboryele, Eli Wisdom Bobo and Charlotte Bakudie. I am grateful to Asifa Majid and the other members of the RU MCC lab for helpful feedback on presentations of the results of this study. I would also like to thank Carolyn O'Meara, Lila San Roque, Niclas Burenhult and two anonymous referees for comments on previous versions of this paper. Thanks to Rebecca Defina for collecting part of the data. This research was supported by a Swedish Foundation for Humanities and Social Sciences Jubilee Initiative Grant (NHS14-1665:1).

\section{Abbreviations}

$\begin{array}{llll}1 & \text { first person } & \text { PFV } & \text { perfective } \\ 2 & \text { second person } & \text { POSS } & \text { possessive } \\ \text { C } & \text { noun class } & \text { POSSM } & \text { possessum pronoun } \\ \text { CM } & \text { clause marker } & \text { POSTP } & \text { postposition } \\ \text { COMP } & \text { complementizer } & \text { POT } & \text { potential } \\ \text { CTR } & \text { contrastive } & \text { PROG } & \text { progressive } \\ \text { DEF } & \text { definite } & \text { PROX } & \text { proximal demonstrative } \\ \text { FOC } & \text { focus } & \text { PURP } & \text { purposive } \\ \text { ID } & \text { ideophone } & \text { QUOT } & \text { quotative } \\ \text { INDF } & \text { indefinite } & \text { REC } & \text { recurrent } \\ \text { INT } & \text { intentive } & \text { REL } & \text { relativizer } \\ \text { LOC } & \text { locative } & \text { SBJV } & \text { subjunctive } \\ \text { LOG } & \text { logophoric } & \text { SVM } & \text { serial verb marker } \\ \text { NEG } & \text { negative } & & \end{array}$

\section{References}

Aikhenvald, Alexandra Y. \& Anne Storch. 2013. Linguistic expression of perception and cognition: A typological glimpse. In Alexandra Aikhenvald \& Anne Storch (eds.), Perception and cognition in language and culture, 1-45. Leiden: Brill.

Ameka, Felix K. 1990. The grammatical packaging of experiencers in Ewe: A study in the semantics of syntax. Australian Journal of Linguistics 10. 139-181.

Ameka, Felix K. 2013. Possessive constructions in Likpe (Sekpelé). In Alexandra Y. Aikhenvald \& Robert M. W. Dixon (eds.), Possession and ownership: A crosslinguistic typology, 224-242. Oxford: Oxford University Press.

Bah, Oumar. 2009. Saggitorde oumar bah [dictionnaire pular]. In RefLex: Reference lexicon of Africa, version 1.1, Paris, Lyon. http://reflex.cnrs.fr/ (accessed 1 October 2018). 
Baker, Collin Freeman. 1999. Seeing clearly: Frame semantic, psycholinguistic, and cross-linguistic approaches to the semantics of the English verb see. Berkeley, CA: University of California dissertation.

Classen, Constance. 1993. Worlds of sense: Exploring the senses in history and across cultures. London: Routledge.

Croft, William. 1998. Linguistic evidence and mental representations. Cognitive linguistics 9. 151-174.

Defina, Rebecca. 2016a. Events in language and thought: the case of serial verb constructions in Avatime. Nijmegen: Radboud University dissertation.

Defina, Rebecca. 2016b. Serial verb constructions and their subtypes in Avatime. Studies in Language 40(3). 648-680.

Dik, Simon C. \& Kees Hengeveld. 1991. The hierarchical structure of the clause and the typology of perception-verb complements. Linguistics 29. 231-259.

Enghels, Renata \& Marlies Jansegers. 2013. On the crosslinguistic equivalence of sentir(e) in Romance languages: A contrastive study in semantics. Linguistics 51(5). 957-991.

Evans, Nicholas \& David Wilkins. 2000. In the mind's ear: The semantic extensions of perception verbs in Australian languages. Language 76(3). 546-592.

Fulkerson, Matthew. 2015. What counts as touch? In Dustin Stokes, Mohan Matthen \& Stephen Biggs (eds.), Perception and its modalities, 191-204. Oxford: Oxford University Press.

Geeraerts, Dirk. 1993. Vagueness's puzzles, polysemy's vagaries. Cognitive Linguistics 4(3). 223-272.

Geurts, Kathryn Linn. 2002. Culture and the senses: Bodily ways of knowing in an African community (Ethnographic Studies in Subjectivity 3). Berkeley, CA: University of California Press.

Guerrero, Lilián \& Irasema Cruz Domínguez. 2017. Feelings as emotion, attitude, and viewpoints. In Brian Nolan \& Elke Diedrichsen (eds.), Argument realisation in complex predicates and complex events: Verb-verb constructions at the syntax-semantic interface, 347-372. Amsterdam \& Philadelphia: John Benjamins.

Howes, David. 2006. Hearing scents, tasting sights: Toward a cross-cultural multi-modal theory of aesthetics. Paper presented at the Art \& The Senses Conference, University of Oxford, 27-29 October.

Ibarretxe-Antuñano, Iraide. 2008. Vision metaphors for the intellect: Are they really cross-linguistic? Atlantis: Journal of the Spanish Association of Anglo-American Studies 30(1). 15-33.

Johnson, Christopher. 1999. Metaphor vs. conflation in the acquisition of polysemy: The case of see. In Masako K. Hiraga, Chris Sinha \& Sherman Wilcox (eds.), Cultural, psychological and typological issues in cognitive linguistics, 155-169. Amsterdam \& Philadelphia: John Benjamins.

Khachaturyan, Maria. 2012. mano. In Guillaume Segerer \& Sébastien Flavier (eds.), RefLex: Reference lexicon of Africa, version 1.1, Paris, Lyon. http://reflex.cnrs.fr/ (accessed 1 October 2018).

Macpherson, Fiona. 2011. Introduction: Individuating the senses. In Fiona Macpherson (ed.), The senses: Classical and contemporary philosophical perspectives, 3-43. Oxford: Oxford University Press.

Majid, Asifa \& Stephen C. Levinson. 2011. The senses in language and culture. The Senses and Society 6(1). 5-18. 
Noonan, Michael. 1985. Complementation. In Timothy Shopen (ed.), Language typology and syntactic description, vol II: Complex constructions, 42-140. Cambridge: Cambridge University Press.

Norcliffe, Elisabeth, N. J. Enfield, Asifa Majid \& Stephen C. Levinson. 2010. The grammar of perception. In Elisabeth Norcliffe \& N. J. Enfield (eds.), Field manual volume 13, 7-16. Nijmegen: Max Planck Institute for Psycholinguistics, Language \& Cognition Group.

van Putten, Saskia. 2014. Information structure in Avatime. Nijmegen: Radboud University dissertation.

Riemer, Nick. 2005. The semantics of polysemy: Reading meaning in English and Warlpiri (Cognitive Linguistics Research 30). Berlin \& New York: Mouton De Gruyter.

Ritchie, Ian. 1991. Fusion of the faculties: A study of the language of the senses in Hausaland. In David Howes (ed.), The varieties of sensory experience: A sourcebook in the anthropology of the senses, 192-202. Toronto: University of Toronto Press.

San Roque, Lila, Kobin H. Kendrick, Elisabeth Norcliffe, Penelope Brown, Rebecca Defina, Mark Dingemanse, Tyko Dirksmeyer, N. J. Enfield, Simeon Floyd, Jeremy Hammond, Giovanni Rossi, Sylvia Tufvesson, Saskia van Putten \& Asifa Majid. 2015. Vision verbs dominate in conversation across cultures, but the ranking of non-visual verbs varies. Cognitive Linguistics 26(1). 31-60.

San Roque, Lila, Kobin H. Kendrick, Elisabeth Norcliffe \& Asifa Majid. 2018. Universal semantic associations are grounded in conversation: Evidence from perception verbs in 13 languages. Cognitive Linguistics 29(3). 371-406.

Sandra, Dominiek. 1998. What linguists can and can't tell you about the human mind: A reply to Croft. Cognitive Linguistics 9(4). 361-378.

Segerer, Guillaume \& Sébastien Flavier. 2011-2018. RefLex: Reference lexicon of Africa, version 1.1. Paris \& Lyon. http://reflex.cnrs.fr/.

Sorabji, Richard. 1971. Aristotle on demarcating the five senses. The Philosophical Review 80(1). 55-79.

Strik Lievers, Francesca. 2007. Italian perception verbs: A corpus-based study. In Andrea Sansò (ed.), Language resources and linguistic theory, 167-179. Milan: Franco Angeli.

Stüwe-Thanasoula, Marilena. 2016. Towards a grammar of the senses: Perception in Lushese (Olussese). Cologne: Universität zu Köln dissertation.

Sweetser, Eve. 1990. From etymology to pragmatics (Cambridge Studies in Linguistics 54). Cambridge: Cambridge University Press.

Thanassoula, Marilena. 2012. The perception verbs in Lussese (Bantu J10): A matter of experience. In Niclas Burenhult, Arthur Holmer, Anastasia Karlsson, Håkan Lundström \& Jan-Olof Svantesson (eds.), Special issue on humanities of the lesser-known: New directions in the description, documentation and typology of endangered languages and musics (Language Documentation and Description 10), 307-328. London: SOAS.

Thanassoula, Marilena. 2013. Perception in Lussese (Bantu, J 10). In Alexandra Y. Aikhenvald \& Anne Storch (eds.), Perception and cognition in language and culture, 251-270. Leiden: Brill.

Treis, Yvonne. 2010. Perception verbs and taste adjectives in Kambaata and beyond. SUGIA-Sprache und Geschichte in Afrika 21. 313-346. https://hal.archives-ouvertes.fr/hal-00719306/.

Tuggy, David. 1993. Ambiguity, polysemy, and vagueness. Cognitive Linguistics 4(3). 273-290.

Tyler, Andrea \& Vyvyan Evans. 2001. Reconsidering prepositional polysemy networks: The case of over. Language $724-765$. 
Vanhove, Martine. 2008. Semantic associations between sensory modalities, prehension and mental perceptions. In Martine Vanhove (ed.), From polysemy to semantic change: Towards a typology of lexical semantic associations, 341-370. Amsterdam \& Philadelphia: John Benjamins.

Viberg, Åke. 1983. The verbs of perception: A typological study. Linguistics 21(1). 123-162.

Viberg, Åke. 2008. Swedish verbs of perception from a typological and contrastive perspective. In Maria de los Ángeles Gómez González, J. Lachlan Mackenzie \& Elsa M. González-Álvarez (eds.), Languages and cultures in contrast and comparison, 123-172. Amsterdam \& Philadelphia: John Benjamins.

de Vignemont, Frédérique \& Olivier Massin. 2015. Touch. In Mohan Matthen (ed.), The Oxford handbook of philosophy of perception, 294-313. Oxford: Oxford University Press. 